before it is shown what founded species-series are still justified, and which must be revised.

Throughout its length, this book impresses one by the author's sense of plants as living things, each posing many problems still but slightly grasped and which must duly be essayed if one should hope to picture near relationships.

Although the major chapters brim with novel observations, they rather seek to urge research than to suggest conclusions. Perhaps the final chapter will serve the most to quicken new inquiry; for, vividly, it turns the mind from plants in cultivation to an understanding of, in part, their fitness to their native habitats and their sustained survival.

This simply written book reflects a long and arduous effort. Its illustration merits special praise, as does its composition. J. MCLEAN ThOMPSON

\section{A POPULAR NATURE STUDY}

\section{Nature through the Year}

By Frances Pitt. Pp. vii +300 . (London: Macmillan and Co., Ltd., 1951.) 18s. net.

GRANCES PITT's literary excursions in natural history are now so well known that there can be few with love of Nature who have not met her in person or print. In her latest work this popular writer presents a colourful account of natural events throughout the year. As always, the book is written in a delightful narrative style which is accompanied by evidence of acute powers of observation stemming from keen interest in and love of living things.

In some ways the title of the book is a misnomer. Although othor aspects of Nature are referred to, Miss Pitt is mainly concerned with birds and mam. mals, and these, not unexpectedly, sometimes include those well-loved pets with which the author has had long acquaintance and studied so carefully. The book, in fact, would serve as an admirable supple. ment to the popular "In Britain" series by the same publishers, particularly if these in turn were strengthened by a work dealing with insects in Britain.

The arrangement of the book is on a woekly basis. Beginning on January 1 and continuing for each successive week throughout the year, the author has recorded significant impressions which she has observed, and has used these as starting points for gentle dissertations on biological principles or practices. An encounter with a hare, for example, leads naturally to discourse about animal camouflage, while genetic principles are introduced after a mild detective story in which a Manx cat is the chief suspect.

In these voyagings Miss Pitt does not hesitate to roam wherever fancy takes her, and one of her weekly episodes begins with an account of a squirrel's reaction to the sting of a wasp, continues with the description of a squirrel which had "bilious" attacks which may have been brought on by eating Brazil nuts, and finishes with possible explanations of old legends about spectral horsemen and ghostly hounds running equally ghostly quarry through the night; these vagaries do not detract from the charm of the book. Nor do some minor errors, although, when another edition of the book is called for, Miss Pitt should not-on p. 73 -begin a sentence by saying that she "could not give a definite answer", and end it with "the reason is undor tt?dly one of light and lighting". So, too, with other parts of the text which appear to have been hastily written and have become so loosely constructed that, as on p. 289 , the author has exposed herself to the charge of anthropomorphism.

The book is generously provided with black-and white illustrations, the photographs for which were taken by Miss Pitt; the majority of these are clear but a few are well below the standard associated with the publishers.

In a world where the search for truth has become so objectively impersonal that much present-day writing lacks the warmth and colour of human emotion, Miss Pitt's book makes refreshing and interesting reading mainly because the author has nowhere tried to conceal her feelings and idiosyncrasies.

Besides British readers, "Nature through the Year" would be an admirable guide for visitors from overseas who have come to examine Britain as she really is in Festival year. T. H. Hawkins

\section{ATOMIC REMINISCENCES}

\section{New Atoms}

Progress and some Memories. By Otto Hahn. A collection of Papers, edited by Dr. W. Gaade. Pp. 184. (New York and Amsterdam: Elsevier Publishing Co., Inc.; London: Cleaver-Hume Press, Ltd., 1950.) 12s. $6 d$.

7 HOUGH there has been a number of books purporting to expound the scientific facts about 'atomic energy' to the non-technical reader, this little volume should hold its own. It is a collection of four lectures, each complete in itself; hence some overlap is unavoidable. The first is the Nobel Lecture given by the author in 1946, and is an account of the work which led up to the discovery of nuclear fission. The occasions on which the other three lectures are given are not stated; the second is largely physical, centred around the nuclear chain reaction which followed soon after the discovery of fission. In the third, the author is at home again in his beloved chemistry, zestfully describing the new elements (no less than ten) which recent nuclear research (not all of it directly connected with fission) has given the chemists to play with. The last brings reminiscences of the early years of radioactivity; less technical and often humorous, it paints a lively canvas of those heroic days when radium was new and anything might happen.

The style is very straightforward, indeed rather subtle in its simplicity. It avoids the long-winded explanations which are apt to stress rather than resolve difficulties, and it is also refreshingly free from that hectic verbiage by which some popular writers lash the flagging attention of their jaded readers. Much of the information given, particularly in the third lecture, is fairly technical; but it is always presented in simple language. Perhaps the most valuable feature is the sense of historical unity, connecting early radioactivity and modern atomic energy, a unity of which the author is a living symbol and which he succeeds very well in communicating.

On the whole, this is a most likeable little book, written by a man who took a leading part in the development of radioactivity and who enjoys telling us about his work and the scientific scenery in which it took place. The translation is good; a few minor slips are easily spotted and do no harm.

O. R. FRISCH 